\title{
Laboreal
}

Volume $4 \mathrm{~N}^{\circ} 1$ | 2008

Ergologia, trabalho, desenvolvimentos

\section{El RH está desnudo : tramas y urdiduras por una gestión colectiva del trabajo}

O RH está nu : tramas e urdiduras por uma gestão coletiva do trabalho Le RH est nu : trames et chaînes pour une gestion collective du travail The HR is naked: trams and warps for a collective work management

\section{Maria Elisa Siqueira Borges}

\section{CpenEdition}

Journals

\section{Edición electrónica}

URL: http://journals.openedition.org/laboreal/11980

DOI: 10.4000/laboreal. 11980

ISSN: 1646-5237

\section{Editor}

Universidade do Porto

\section{Referencia electrónica}

Maria Elisa Siqueira Borges, «El RH está desnudo : tramas y urdiduras por una gestión colectiva del trabajo », Laboreal [En línea], Volume 4 N$^{0} 1$ | 2008, Publicado el 01 julio 2008, consultado el 24 septiembre 2020. URL : http://journals.openedition.org/laboreal/11980 ; DOI : https://doi.org/ 10.4000/laboreal.11980

Este documento fue generado automáticamente el 24 septiembre 2020.

Laboreal está licenciado com uma Licença Creative Commons - Atribuição-NãoComercial 4.0 Internacional. 


\title{
El RH está desnudo : tramas y urdiduras por una gestión colectiva del trabajo
}

\author{
O RH está nu : tramas e urdiduras por uma gestão coletiva do trabalho \\ Le RH est nu : trames et chaînes pour une gestion collective du travail \\ The HR is naked : trams and warps for a collective work management
}

\section{Maria Elisa Siqueira Borges}

\section{REFERENCIA}

Borges, M. E. (2006) O RH está nu : tramas e urdiduras por uma gestão coletiva do trabalho. Tese de Doutoramento. Programa de Pós-graduação em Psicologia Social da Universidade do Estado do Rio de Janeiro, Rio de Janeiro/Brasil.

\section{NOTA DEL EDITOR}

Manuscrito recibido en : abril/2008

Aceptado tras peritage en : junio/2008

\section{Introducción}

1 El principal objetivo de la tesis fue comprender/transformar la actividad de los profesionales de "Recursos Humanos" (o "Gestión de Personas", o Gestión del Trabajo, como preferi- mos). Utilizamos durante toda la tesis una metáfora construida a partir del cuento de Hans Christian Andersen : El Rey va des- nudo. Se trata de la historia de un rey que fue engañado por tejedores trapaceros que prometieron vestirlo con un traje be- llo y carísimo que sólo podría ser visto por personas inteligen- tes. Esta 
historia aliada a la metáfora utilizada por Daniellou (2004) para referirse al trabajo (la trama y la urdidura) dio origen al título y se convirtió en el hilo conductor de la tesis.

2 En una perspectiva ergológica, buscamos investigar en el co- tidiano del trabajo de profesionales de Gestión de Personas, ¿qué tipo de gestión hacen esos profesionales? ¿Qué posibili- dades de actuar desarrollan ellos, teniendo en vista las actua- les exigencias del capitalismo en los mundos del trabajo y las prescripciones que de ahí advienen? En la gestión que hacen de su trabajo, de su actividad, ¿qué (im)posibilidades están ahí contenidas, en el sentido de desarrollar una gestión colectiva del trabajo, una ergogestión?

3 La misma denominación de ese "campo" de actuación fue puesta en análisis. Hablar de los humanos como recursos o afirmar la pretensión de gestionar personas parece partir de una misma suposición : el de que las 'personas' - como los demás recursos - no son protagonistas activos de su vida y su trabajo, son apenas agregadas en cuanto fuerza de trabajo en la producción de valor de capital y se someten a él, como simples soportes de una pura heterodeterminación. Remite a la idea de que las personas necesitan ser administradas o gestionadas para mejor poder realizar su trabajo. Peor, creen en la posibilidad de que las personas sean gestionables...

4 Se defendió la idea de mirar hacia los colectivos de trabajo no en esta óptica, pero como protagonistas de la actividad en foco, trabajadores (individuales y colectivos) que hacen ya su trabajo gestionándolo colectivamente, en alguna medida. Y quieren desarrollar esta potencia de vida. En la medida en que no se admite, reconoce, valora, evalúa esa gestión que es practicada, cotidianamente, en los mundos del trabajo, un planteamiento que objetiva "administrar recursos" o "gestio- nar personas" se convierte en un obstáculo ético-epistemoló- gico al desarrollo teórico-metodológico-técnico de ese campo. Se destacó la fragilidad, en todos los planos, de este ' $\mathrm{RH}^{\prime}$ o 'GP'. Por un lado, se encuentra en plena evidencia delante de la importancia que ganó a partir de las transformaciones tec- nológico-organizacionales contemporáneas. Por otro, en ple- na fragilidad por no presentar una reflexión y sistematización teórico-metodológica y de práctica técnico-profesional de in- tervención a la altura de la nobleza de lo que está en juego. A remolque del "saber" de consistencia científicamente dudo- sa, el RH se ha dejado llevar por valores "de momento", asu- miendo fisionomías diferenciadas de acuerdo con las exigen- cias coyunturales del capitalismo y de la formación social brasileña (importadora de tecnologías, incluso de gestión). Todo parece caber en las prácticas de $\mathrm{RH}$, desde las prácticas más serias hasta las más manipuladoras y/o mediocres y me- diocrizantes. Prácticas que, muchas veces, insisten en simpli- ficar mutilando - la complejidad de la vida, de los humanos y del trabajo humano.

\section{Referenciales teóricos}

5 Se usó como punto de partida teórico la distinción apuntada por la Ergonomía de la Actividad entre "trabajo prescrito" y "trabajo real", a partir de la cual la Ergología hace una rica elaboración, agregando aportaciones en el sentido de am- pliarla, transformarla. Los conceptos de gestión de si (del cuerpo-si) y dramáticas del uso de si, así como el paradigma ergológico, con su dispositivo dinámico de tres polos - DD3P (Schwartz \& Durrive, 2007) fueron esenciales para la com- prensión del problema de la tesis y su desarrollo, llamando la atención para la complejidad del trabajo, su carácter siempre enigmático, del punto de vista transversal de la actividad. Los materiales de la 
Clínica de la Actividad y de la Lingüística Dialógica (envolviendo particularmente Yves Clot y Daniel Faïta, (Clot, Faïta, Fernandez \& Scheller, 2001) evidenciaron la importancia de la actividad charlatana para comprender el trabajar y el papel que ella desempeña en la misma construc- ción de la actividad de trabajo.

\section{Metodología}

6 Teniendo la Ergología como orientación, trayendo en su inte- rior las experimentaciones del Modelo Obrero Italiano de lucha por la salud - MOI (Oddone, Briante \& Re, 1981), movilizamos herramientas de la Ergonomía de la Actividad y de plantea- mientos clínicos del trabajo, especialmente la Clínica de la Actividad. Constituimos la modalidad de dispositivo dinámico de tres polos que hemos operado en Brasil, que denominamos Comunidad Ampliada de Pesquisa - CAP (Brito \& Athayde, 2003), donde circula una comunidad dialogística. Con la participación de los profesionales de un sector del Banco de Brasil denominado 'Gestión de Personas' (Gepes) y profesionales de pesquisa en Psicología del Trabajo y Lingüística Dialogística, utilizamos como dispositivo-clave los "Encuentros sobre el Trabajo" de la Comunidad Ampliada de Pesquisa. Estos en- cuentros permitieron la creación de un espacio de diálogo- debate sobre la actividad, reuniendo a profesionales del saber disciplinar y los protagonistas de la actividad en foco.

7 Entendemos que el dispositivo creado facilitó la expresión de la actividad de trabajo de esos profesionales, su reflexión y desarrollo.

8 Fueron realizados seis encuentros con la participación de 20 profesionales (17 de Gepes y 3 pesquisadores). Los profesio- nales de Gepes variaban según la edad (menos de 30 a más de 50 años); formación (Psicología, Pedagogía, Medicina, De- recho, Economía, Ciencias Contables, Administración, Fonoau- diologia); tiempo de experiencia en Gestión de Personas (me- nos de un año a más de diez años). De entre los pesquisadores, estaban la autora de esta tesis, una auxiliar de pesquisa, doctoranda en Psicología del Trabajo y una doc- tora en Lingüística. Los encuentros fueron realizados en la Gepes en horario normal de expediente de trabajo y el criterio para participar en el grupo fue la adhesión voluntaria.

\section{Análisis}

9 El análisis de los materiales producidos apuntó algunas "pis- tas" para las posibilidades del desarrollo de una dada gestión colectiva del trabajo, una ergo-gestión :

1. Los profesionales de la Gepes utilizaron muchas y bellas metáforas para hablar de su trabajo: el "curativo" para expre- sar lo que hacen con las personas que los buscan; el "embu- do" o el "cuello de la botella" para representar la comunica- ción dentro de la empresa ; la "goma" significando la forma como ellos amortiguan las "martilladas" que los "funciona- rios-clavos" reciben de sus gerentes. A través de esas metá- foras ellos expresaron las "dramáticas de uso de si" que po- nen en acción al hacer la gestión de su actividad, además de las contradicciones, precariedades e impedimentos. Los dis- positivos utilizados facilitaron la expresión de esas metáfo- ras, provocándolos al movimiento, incluso discursivo. Eso posibilitó a aquél colectivo de trabajo se distanciase de la experiencia vivida para transformarla a la mitad para producir otras experiencias, desarrollando su poder de actuación, con- forme propuesta de Vigotski (1998), desarrollada por la Clíni- ca de la 
Actividad. A través del uso de metáforas, el ‘colectivo Gepes' reveló trazos de la competencia que buscan operar para gestionar colectivamente su trabajo. Demostraron que, a pesar de las inevitables paradojas del trabajo, de los impedi- mentos y sus propias limitaciones en el plan teórico-metodo- lógico (por la ausencia de un patrimonio más rico), inventan medios para seguir trabajando, evidenciando las tensiones permanentes en las dramáticas de usos de si.

2. Ellos identificaron que haber trabajado anteriormente en las agencias del Banco representa un patrimonio, un ingrediente de la competencia necesaria para realizar su trabajo. De esta forma, al enfrentarse con la realidad de su trabajo, reivindican el punto de vista de la actividad como herramien- ta de trabajo. En este sentido, el 'colectivo Gepes', en su cotidiano de trabajo, no es pasivo a los obstáculos que encuen- tra, asumiéndolos como retos.

3. Reconocieron a través de metáforas (especialmente la me- táfora del curativo: en algunos momentos es apenas manipu- lación, en otros momentos surte el efecto deseado) que los recursos genéricos que utilizan para trabajar presentan una doble cara 'funcionar/no funcionar', lo que evidencia un géne- ro profesional frágil, fragmentado y dividido. Pero, en el mo- vimiento del diálogo, al re-elaborar colectivamente las metá- foras, el colectivo Gepes apuesta en la positividad (en el curativo que efectivamente cura), en la posibilidad contenida en el lado Gepes que funciona, "a pesar de todo".

4. El colectivo Gepes utilizó frecuentemente verbos de movi- miento para referirse a la pareja oír/escuchar, trayendo hacia el debate en la CAP una escucha que envuelve "estar cerca para poder oír", "mirar hacia las personas", "llegar juntos”, "ir a don- de está el Banco". De esta forma, ellos expresaron una concep- ción nada pasiva de esa escucha-acción, que envuelve movi- miento, actividad ("tener sensibilidad", tener "postura activa"); una escucha directamente relacionada con un cuerpo-si que va más allá de lo biológico, en la verdad una "entidad colectiva relativamente pertinente" (Schwartz, Y. \& Durrive, L., 2007), un cuerpo social, físico, institucional, atravesado por normas, valo- res, relaciones con el tiempo, con los hombres, etc.

5. Al utilizarse una charla referente al cuidado que es necesa- rio tener con el otro en la "Gestión de Personas" (“cuidar", “acoger", "coger en brazos", "amparar") apuntan al hecho de que frente a las dificultades que surgen en situaciones en que no hay prescripciones pertinentes, ellos recurren a otro gene- ro, disponible para las mujeres, el genero de gestionar matriz : madre/maternidad/familia. El cuerpo-si tiene ahí un papel de- cisivo, una racionalidad del pathos, de la afección, de la pa- sión humana y ellos expresan en las palabras y en la lógica de este género, el "coger en brazos", el "cariño", la "acogida". Pero la motricidad del diálogo también evidenció un tipo de racionalidad, que "analiza", que "evalúa", que "juzga", verbos que ellos utilizaron diversas veces, evidenciando el uso de un tipo de inteligencia más racional, que no solamente la del cuerpo y de la astucia (Dejours, 1992). ¿Una gestión colectiva del trabajo no tendría que operar colaborando para poner esas inteligencias en sinergia, en una 'zona de desarrollo'?

6. Cuestionaron el sentido de que la GP sería el "lugar privile- giado" para gestionar las dialécticas entre el polo mercantil que visa el lucro y el polo político relativo al bien común (Schwartz \& Durrive, 2007), sin creer que es posible que un único sector de la empresa pueda tener el monopolio de ges- tionar esa dialéctica o poseer el monopolio de gestión de las cuestiones humanas en la empresa - lo que es absolutamente simplificador y mutilador.

\section{Consideraciones finales}

10 De una manera general, podemos afirmar, a partir de la pes- quisa que conocer, asumir y valorar la dimensión del gestio- nar que cada humano hace de su trabajo (recentrándolo, ha- ciéndolo suyo), desarrollando esa gestión colectiva, implica en "mirar con lupa", el trabajo, interpelar sus procesos, pre- sentar problemas concretos y 
negociar colectivamente posi- bles soluciones, saliendo, así de falsos debates. $Y$ es esto lo que el colectivo Gepes reivindica, no apenas en un nivel idea- lizado del trabajo (la "conciencia ideal"), pero también en el plano de lo realizado y de lo real de la actividad.

Con relación a la actividad de los profesionales de RH, esta tesis ofrece pistas en la búsqueda de herramientas teórico- metodológico-técnicas que operen con el punto de vista de la actividad (habitualmente ausente en los análisis de esos pro- fesionales), en el sentido del desarrollo de una gestión colec- tiva del trabajo. Colocar este punto de vista como centro de los debates sobre el trabajo puede hacer avanzar algunas cuestiones tan caras a las empresas y a los "RH", en particu- lar, como: desempeño, motivación, productividad \& calidad (de trabajo y de vida), salud, confiabilidad y seguridad

\section{BIBLIOGRAFÍA}

Brito, J. \& Athayde, M. (2003). Trabalho, educação e saúde : o ponto de vista enigmático da atividade. Trabalho, Educação e Saúde 1(2) : 239-265, 2003. http://www.revista.epsjv.fiocruz.br.

Clot, Y., Faïta, D., Fernandez, G. \& Scheller, L. (2001). Entretiens en Auto- confrontation Croisé : un méthode en clinique de l'activité. Educa- tion Permanente, 146, pp. 17-27.

Daniellou, F. (2004). A Ergonomia em Busca de seus Princípios. Debates epistemológicos. São Paulo : Ed. Edgard Blücher.

Dejours, C. (1992). A loucura do trabalho. São Paulo : Cortez/Oboré. Oddone, I., Briante, G. \& Re, A. (1981). Redécouvrir l'Expérience Ouvrière : vers une autre psychologie du travail ? Paris : Ed. Sociales.

Schwartz, Y. \& Durrive, L. (org.) (2007). Trabalho \& Ergologia : conversas sobre a atividade humana. Niterói : Editora da Universidade Federal Fluminense.

Vygotski, L. S. (1998). A formação social da mente : o desenvolvimento dos processos psicológicos superiores. Michael Cole et all. (Ogs.). São Paulo : Martins Fontes.

\section{AUTOR}

\section{MARIA ELISA SIQUEIRA BORGES}

Diálogos - Consultoria em Gestão com Pessoas ; Grupo de Pesquisa Actividade CNpq, Rua Peri 299 ap.103 - CEP 224-100 - Rio de Janeiro RJ Brasil

melisaborges@uol.com.br 